\title{
Aguerracontra as crianças: práticas de sequestro,
desaparecimento e apropriação
de identidade no século xx
}

Enrique Serra Padrós*

O século XX tem sido definido como um período extremamente violento. Conflitos bélicos internacionais - de proporções variadas -, guerras civis, disputas étnica, lutas sócias e terrorismo de Estado, entre tantas outras formas de violência deixaram a sua marca em tão conturbado espaço de tempo. A violência contra as crianças tem sido recorrente nesse processo histórico da contemporaneidade. Vítimas inocentes diante de qualquer circunstância, são alvos diretos ou indiretos de sistemas de poder ou de lógicas beligerantes que neles distinguem, simultaneamente, duas possibilidades de leitura: ou são potenciais inimigos (internos ou externos), ou são parte daquilo que se denomina de "butim de guerra". Sendo assim, o presente artigo resgata experiências

\section{Introduçã̃or}

presente artigo analisa as experiências do sequestro de crianças durante a dinâmica repressiva das ditaduras de Segurança Nacional argentina e uruguaia, entre as décadas de 70 e 80 . A apropriação desse "butim de guerra", como se tornou conhecida essa prática do Terrorismo de Estado platino, teve outras experiências correlatas no

\footnotetext{
*Doutor em História. Departamento e PPG-História/UFRGS. lola@adufrgs.ufrgs.br

${ }^{1}$ As primeiras reflexões sobre esta temática surgiram no contexto do Simpósio Internacional: "Centro, Periferia e Análise Histórica", organizado pelo Programa de Pós-Graduação em História-UFRGS, sob a coordenação do professor José Rivair Macedo, em abril de 2009.
} 
históricas de apropriação de crianças promovidas pelas experiências do franquismo, nazismo, conflitos étnicos africanos e ditaduras de segurança nacional do Cone Sul.

Palavras-chave: desaparecidos - apropriação de crianças - soldados mirins

The twentieth century has been defined as an extremely violent period. International armed conflicts - in varying proportions civil wars, ethnic disputes, fights and members of state terrorism, among many other forms of violence have left their mark in such a troubled time. Violence against children has been recurrent in this historic pro- cess of contemporaneity. Innocent victims before any circumstance, are direct or indirect systems of power or belligerent logical that distinguish them simultaneously two possibilities reading targets: or are potential enemies (internal or external), or are part of what is called a "war booty. "Therefore, this article captures historical experiences of appropriation of children promoted by experiences from Francoism, Nazism, African ethnic conflicts and national security dictatorships of the Southern Cone

Keywords: disappearance - children appropriation - child soldiers

transcorrer do século XX e início do XXI. Neste sentido, resgatam-se outras três experiências concretas contextualizadas, respectivamente, na Europa sob ocupação nazista, na Espanha franquista e na África dos anos 90, como forma de apontar para a persistência destes mecanismos de opressão, geradores de pânico e imobilismo no conjunto da população, responsáveis por traumas de consequências imprecisas e de crimes que se projetam ao longo do tempo e ficam como feridas expostas que perpassam diversas gerações.

Dentro da lógica da lógica dos casos em questão, as formas de violência contra as crianças, motivadas por critérios de ordem ideológicos, políticos ou raciais, são produto de iniciativa estatal ou, no mínimo, contam com a cumplicidade da sua omissão. Seja como for, políticas de silenciamento e de anestesiamento constituem um elo comum para apagar os rastos destes crimes de lesa-humanidade.

\section{As crianças perdidas do franquismo}

O primeiro caso está vinculado com o terrível conflito que atingiu a Espanha na segunda metade dos anos 30 (a Guerra Civil) e que gerou desdobramentos que se prolongaram por quase quatro décadas. Ao final da Segunda Guerra, os exilados republicanos espanhóis, que lutaram nas 
filas antifascistas contra o nazismo, solicitaram aos aliados que acolhessem o pedido de incluir a ditadura franquista entre os aliados do Eixo. Se isto tivesse ocorrido, ter-se-ia dado visibilidade para uma prática de desaparecimento que acabou encoberta por um manto de silêncio durante décadas. Desde o levante da direita espanhola e o início da Guerra Civil decorrente, em 1936, a Espanha foi sacudida por um conflito que teve, entre outras modalidades de violência, os "passeios", ações em que simpatizantes de uma facção eram levados pelos partidários da outra para caminhadas, geralmente em horários noturnos, em lugares ermos, despovoados, e então eram executados. O que durante muito tempo foi considerado uma prática comum das vicissitudes da violência espanhola (vinganças pessoais, revanchismos, desavenças da política local, etc.), acabou se configurando, posteriormente, como situações desproporcionais entre os dois campos em confronto.

Se é bem verdade que do lado republicano isso acontecia, era em proporção muito inferior em comparação ao lado franquista, além de ser motivado por questões individuais, de grupos políticos ou como desencadeamento de uma onda de violência popular. Não era, definitivamente, uma política de governo da Frente Popular, a qual podia organizar julgamentos e até condenar à morte alguns acusados de traição ou de sabotagem. Mas não se pode esquecer que era o poder constituído, democraticamente eleito, que reagia diante da traição, da insurreição golpista das Forças Armadas e da forte presença de forças invasoras. Mas o fazia publicamente, como Estado agredido. O que pode ser ponderado é que, nas regiões nas quais o golpe franquista foi resistido, grupos radicais que assumiram o comando local em nome da revolução e do antifascismo promoveram perseguições e execuções. Mas isto foi decorrência também do esfacelamento regional do governo da Frente Popular.

Já no território que, paulatinamente, foi caindo nas mãos do franquismo, tornavam-se cada vez mais concretas as evidências de que as execuções eram uma política deliberada de Estado praticada pelo Exército e pela Falange Espanhola e justificada pela Igreja Católica, como aponta o historiador britânico Paul Preston; ou seja, consistia numa verdadeira lim- 
peza dos simpatizantes da República. ${ }^{2}$ Curiosamente, só nos últimos anos a sociedade espanhola passou a ter noção dos milhares de cidadãos que foram sequestrados, vítimas de "passeios" e enterrados em valas comuns e desconhecidas; pessoas desaparecidas que não foram mortas em combate, mas retiradas dos cárceres, onde estavam presas sem julgamento, ou que estavam na cota dos $10 \%$ de suspeitos de "rojillos" a serem eliminados, estabelecida pelos oficiais golpistas quando suas tropas entravam nos vilarejos. ${ }^{3}$ Portanto, os restos mortais das vítimas foram, em última instância, desaparecidos pelo franquismo. Informações e denúncias de existência de fossas comuns, fuzilamentos massivos, existência de milhares de famílias que perderam integrantes durante os anos do conflito e os anos posteriores, de feroz ajuste de conta promovido pelo Estado, abalam a sociedade espanhola mesmo quase 70 anos após o início do conflito interno.

Setores importantes da sociedade, organizações de direitos humanos, fóruns em defesa da memória e associações democráticas assumiram o que passaram a considerar como o caso dos "desaparecidos" espanhóis (o mais emblemático é o de Federico García Lorca). A Asociación para la recuperación de la memoria histórica levantou mais de 2 mil casos de desaparecimento de pessoas vítimas do franquismo entre os anos de 1936 e 1949. A denúncia e descoberta de valas comuns da Guerra Civil levaram, em 2002, o Grupo de Trabalho sobre Desaparições Forçadas, vinculado ao Alto Comissariado para os Direitos Humanos da ONU, a incluir a Espanha na lista de países que possuem desaparecidos. ${ }^{4}$

${ }^{2}$ Cf. VÁSQUEZ MONTELBÁN: Manuel. Los Desaparecidos. Interviú, Madrid, 11 dic. 2000, [s.p.]; OTERO, Lisandro: Las llagas del franquismo. Rebelión, Madrid, 20 jun. 2009, [s.p.]. Também os documentos: FORO POR LA MEMORIA. La represión en ambas zonas, características, estudios y fiabilidad. Memoria Republicana. Disponível em: <http://www. pce.es/foroporlamemoria>. Acesso em: 2 jul. 2009; EQUIPO NIZKOR \& DERECHOS HUMAN RIGHTS. La cuestión de la impunidad en España y los crímenes franquistas. Disponível em: <http://www.derechos.org/nizkor/espana/doc/impesp.html>. Acesso em: 28 jun. 2009; Carlos CUÉ. "La recuperación de la memoria antifranquista". El País, Madrid, 20 sep. 2004, [s.p.].

${ }^{3}$ CRUZ GONZÁLEZ, Antonio: ¿Desaparecidos ou desperdigados? Rebelión, Madrid, 14 feb. 2004, [s.p.].

${ }^{4}$ Las fosas de la represión fascista colocan a España en la lista de desaparecidos de la ONU. 
Uma das modalidades de desaparecimento sobre as quais estão se voltando pesquisas recentes é o sequestro e desaparecimento de aproximadamente 12 mil crianças, a maioria constituída de órfãos de guerra com pais mortos, presos, exilados, clandestinos ou desaparecidos (documentos oficiais indicam só a condição de fuzilados ou desaparecidos). Considerando a ausência do pai e o esfacelamento das famílias republicanas, essas crianças foram obrigadas a acompanhar as mães quando encarceradas e sofreram altos índices de mortalidade resultantes das péssimas condições de sobrevivência existentes. No caso das mães serem condenadas a penas muito longas ou à pena de morte, procedia-se à expropriação imediata. A Igreja Católica colaborou e co-participou desta ação, encobrindo o encaminhamento das crianças a orfanatos católicos e a famílias simpatizantes da nova ordem. ${ }^{5}$ Seu atual silêncio sobre tais acontecimentos e sobre os livros de registro de batismo (sabendo-se que, ao final da guerra civil, centenas de crianças eram batizadas semanalmente nos locais de Auxílio Social ${ }^{6}$ ), acaba sendo profundamente constrangedor.

O objetivo essencial do regime, quanto aos filhos dos marxistas (republicanos, rojillos), era sua reeducação; esta passava, necessariamente, pela erradicação ideológica do inimigo. Foi com esse intuito que os filhos dos republicanos eram apropriados, para poder semear neles a doutrina do regime (nacional-sindicalismo e nacional-catolicismo) e a rejeição das idéias do entorno familiar e social. A eficiência dessa ação se comprova diante dos relatos de mães que, após anos de busca atrás de pistas dos filhos roubados, os encontraram educados dentro de uma concepção de ódio visceral aos republicanos.

Rebelión, Madrid, 21 jun. 2003, [s.p.].

${ }^{5}$ Ley de 23 de noviembre de 1940 sobre Protección de Huérfanos. In: VINYES, Ricard; ARMENGOU, Moutse; BELIS, Ricard. Los niños perdidos del franquismo. Barcelona: Plaza Janés, 2002, pp. 218-222.

${ }^{6}$ Instituição vinculada à seção feminina da Falange Espanhola, posteriormente colocada sob a órbita do Estado. Administrava orfanatos e hospícios através de trabalho e doações voluntários. Foi vital para o processo de sequestro e apropriação de crianças. Ideologicamente coincidia com as premissas de que salvar filhos de marxistas e ateus era tarefa caridosa e cristã. 
Há dados que apontam que, em 1943, havia cerca de 12.042 crianças nessas condições - portanto, sob tutela do Estado -, em centros religiosos e em estabelecimentos públicos. A apropriação ocorria dentro das instalações do próprio Estado, nas instituições do Auxílio Social e nos cárceres lotados de presas grávidas ou com filhos. Para agilizar o sequestro de identidade, o regime aprovou que a pátria potestade de todas as crianças que entravam no Auxílio Social passava às mãos do Estado, o qual, desta forma, podia alterar seu nome e entregá-las a famílias confiáveis. Os recém-nascidos em prisão eram retirados pouco antes do fuzilamento das mães. Outras tantas crianças foram raptadas no exterior, dos campos de concentração onde estavam detidos os exilados. Estas ações eram de responsabilidade do Serviço Exterior da Falange (o partido único do franquismo e de filiação predominantemente fascista, pelo menos até 1942).

Cabe registrar que as crianças desaparecidas da Espanha não foram assassinadas - pelo menos não há prova ou testemunho disso -, mas tampouco foram devolvidas às famílias ou aos pais verdadeiros (em caso de sobrevivência destes). O Estado as fez desaparecerem, reeducou-as dentro dos preceitos do novo regime e lhes expropriou a origem, a história e a identidade, ${ }^{7}$ segundo Vinyes, Armengou e Belis, na sua obra coletiva:

[nuestros niños perdidos] lo son en cuanto que "perdida" significa la privación del derecho que tenían a ser formados por sus padres o familiares, los cuales perdieron a su vez el derecho de criarlos según sus convicciones. [...] también significó la desaparición física por un largo período de tiempo, o para siempre. Este conjunto de situaciones fue el resultado de prácticas de sustracción violenta amparadas por una legislación de naturaleza ideológica, pero encubiertas y desfiguradas por una aparente intención misericordiosa de protección a estos niños, una actuación imposible de realizar sin la muy activa intervención de la Iglesia católica. ${ }^{8}$

Comparando com o sequestro e apropriação de crianças praticados pela ditadura argentina das Juntas Militares, os autores concluem que, no

\footnotetext{
${ }^{7}$ España: Los 12 mil desaparecidos de Franco. Rebelión, Madrid, 21 abr. 2002, [s.p.].

${ }^{8}$ VINYES, Ricard; ARMENGOU, Moutse; BELIS, Ricard. Op. cit. , p. 60. 
caso espanhol, o desaparecimento resultou da depuração produzida pelo Estado entre os vencidos. Tal ação não foi clandestina, como no caso platino, mas foi um processo institucionalizado, legal, administrativo e burocrático, perpetrado pela nova ordem e facilitador dos desaparecimentos. ${ }^{9} \mathrm{O}$ capítulo das "crianças perdidas" resultou do entendimento de que filhos de pais republicanos deviam ser separados destes (esta consigna básica foi repetida nos casos platinos posteriores: filho de subversivo, subversivo será). A ação conjunta do Estado e da Igreja, através da legislação específica, do Auxílio Social e das escolas católicas tornou-se um poderoso e agressivo mecanismo de reorientação política (objetivando a doutrinação religiosa e fascista e a introjeção de uma disciplina militar). ${ }^{10}$

Até meados dos anos 90 a sociedade espanhola reconhecia como seus únicos cidadãos desaparecidos somente os espanhóis atingidos pela voragem dos anos de chumbo latino-americanos. O caso Pinochet (sua detenção na Inglaterra e a polêmica sobre a extradição solicitada pelo juiz Baltazar Garzón) e o debate sobre a legitimidade da jurisdição espanhola para atuar nos crimes cometidos contra seus cidadãos no Cone Sul conscientizaram parte da sociedade do país sobre o anestesiamento da sua própria história. Deste modo houve uma (re)descoberta de uma situação específica vinculada à Guerra Civil e à ditadura franquista. Baltazar Garzón tipificou como crimes contra a humanidade a ação repressiva desencadeada pelo franquismo. Segundo ele, houve um plano sistemático e preconcebido de eliminação da oposição política através de sequestros, execuções, tortura e exílio. ${ }^{11}$ Diante de tudo isso, a sociedade espanhola vem se apropriando do conceito e da identidade dessas duas figuras históricas e concretas, o desaparecido e a criança de identidade apropriada, conhecidas por causa da experiência latino-americana de Segurança Nacional; desde então, há um embate tra-

\footnotetext{
${ }^{9}$ Ibid., p. 81 .

${ }^{10}$ Victoria BURNETI. Espanha investiga crianças perdidas sob o regime de Franco. Disponível em: <http://www.ar.terra.com/tecnologia/interna/0,013615016-18142,00.html > . Acesso em: 4 jul. 2009.

${ }^{11}$ YOLDI, José. Garzón insta a siete juzgados a investigar los 'niños robados' del franquismo. El País, Madrid, 9 ene. 2009, [s.p.].
} 
vado, o da luta pela recuperação da memória e da história das vítimas do Terrorismo de Estado promovido pelo franquismo. ${ }^{12}$

\section{Filhos do "lebensborn": a super-raça nazista}

O segundo caso em questão faz parte da história da expansão nazista e de suas idéias, pelo continente europeu. $\mathrm{O}$ sequestro de crianças foi uma prática sistemática do Estado nacional-socialista e esteve vinculado com a sua percepção racial do mundo e as necessidades de fomentar o crescimento demográfico ariano em curto espaço de tempo. A relação entre expansão territorial desejada (a conquista do "espaço vital") e um fator demográfico considerado insuficiente se combinaram com o entendimento de que a raça ariana estava cercada por raças impuras e inferiores. Esta situação levou as autoridades do III Reich a promover o sequestro de crianças cujas características genéticas eram consideradas, segundo eugenistas nazistas, aptas para serem germanizadas ou escravizadas. Crianças polonesas, tchecas, russas, iugoslavas, etc., foram sequestradas pelas SS. Só na Polônia, mais de 200 mil crianças sofreram essa prática e foram separadas das suas famílias. ${ }^{13} \mathrm{O}$ chefe nazista Hanz Frank até escreveu no seu diário: "Quando penso que, com esses olhos azuis e esses cabelos louros, elas falam polonês, custa-me a acreditar". ${ }^{14}$

A apropriação dessas crianças durante a guerra objetivou reduzir a pressão populacional dos países vizinhos da Alemanha e, simultaneamen-

\footnotetext{
${ }^{12} \mathrm{O}$ Congresso espanhol aprovou, em 20 de novembro de 2002, por unanimidade, uma resolução de condenação ao franquismo e reconhecimento moral das vítimas da Guerra Civil e do regime de Franco. Entre as medidas aprovadas, está o apoio institucional às iniciativas destinadas à exumação de cadáveres não identificados do conflito interno enterrados em fossas comuns espalhadas por todo o território espanhol.

${ }^{13}$ No Julgamento de Nüremberg, foram apresentadas provas que identificavam o sequestro de 50 mil crianças dos países da Europa central, 50 mil da Hungria (Rutênia) e mais de 100 mil jovens poloneses escravizados a partir das Operações Forquilha e Barão Cigano. Cf. HILLEL, Marc. Em nome da raça. Os "haras" nazistas. Rio de Janeiro: Hachette, 1975, p. 193.
}

${ }^{14}$ Ibid., p. 193. 
te, enriquecer seu próprio povo com crianças consideradas "racialmente valiosas". Para levar adiante esse empreendimento, foram envolvidos inúmeros organismos como o Comissariado do Reich para a Consolidação da Raça Germânica e o Departamento Superior da Raça e do Povoamento (RUSHA). ${ }^{15}$ De particular importância e vinculada à RUSHA era a organização SS Lebensborn (Fontes da Vida). A mesma administrava uma gigantesca maternidade estatal que estimulava o "cruzamento" entre mulheres arianas e jovens SS com finalidade procriativa. Na prática, consistia de um programa que criara uma infra-estrutura material de residências secretas na Alemanha e na Europa ocupada para que homens e mulheres "racialmente puros" mantivessem relações sexuais. Jovens mulheres, convencidas pela propaganda oficial que as convidava a oferecer um filho para o führer, aguardavam a visita de grupos de jovens SS com a finalidade de engravidar e, como incubadora humana, oferecer o seu ventre ao esforço nazista de construção do Terceiro Reich. As crianças geradas podiam ficar com elas ou, se assim o desejassem, sob o encargo do Estado (criação, educação e formação), em instituições criadas especificamente para isso.

Mas o Lebensborn também se encarregava das crianças sequestradas. Os critérios de escolha das mesmas priorizavam a beleza (segundo os parâmetros arianos vigentes - olhos azuis, cabelos loiros, pele branca), as condições de saúde, os níveis de inteligência e aptidões físicas. Depois de avaliadas, essas crianças, se consideradas aptas, eram germanizadas; do contrário, eram abandonadas, devolvidas aos pais ou, em caso de existência de impureza racial, enviadas aos campos de concentração. O processo de germanização ocorria ao dar-lhes uma identidade alemã e uma espécie de patrimônio germânico: data e local de nascimento, língua, padrão cultural e ideológico e habilitação para serem inseridas nas organizações e nas instituições estatais de educação e recreação. As crianças apropriadas passavam por um processo de reciclagem de uns seis meses.

\footnotetext{
${ }^{15}$ Instituição encarregada de administrar e executar os exames raciais. Decidia a escolha das crianças que deviam ser raptadas ou que eram consideradas descartáveis (passíveis de serem exterminadas). Também determinava quais as mulheres que deviam abortar e/ou ser esterilizadas.
} 
A idade era um critério lógico considerando a expectativa de sucesso esperada no processo de apropriação. Até essa idade, as crianças mostravam-se mais receptivas ao ensino da Weltanschaung (concepção nazista de mundo); além disso, a ausência de recordações tornava mais fácil a assimilação e a falsificação da sua identidade. Ou seja, possibilitava maior eficiência naquilo que, posteriormente, nos países platinos, as organizações de direitos humanos denominariam de apropriações.

O sequestro podia ser massivo ou individual. No primeiro caso, as crianças detidas nas escolas ou reunidas nas praças das cidades e dos vilarejos dos territórios ocupados eram mandadas para campos de triagem, onde médicos e especialistas em higiene racial determinavam as assimiláveis e as "não-aproveitáveis" (destas, algumas eram devolvidas, entretanto, a maioria terminava nos campos de extermínio). No caso do rapto individual, destacavam-se as unidades das "irmãs pardas das SS", constituídas por mulheres vestidas com uniformes dessa cor, treinadas para localizar e identificar crianças passíveis de assimilação. Para tanto, eram treinadas em estágios onde se especializavam no conhecimento e na identificação de características raciais desejadas. Desses cursos, também faziam parte técnicas de rastreamento, abordagem e sequestro de crianças.

Como mecanismo de abordagem, as "irmãs pardas" usavam o expediente de oferecer guloseimas enquanto simulavam uma conversa despretensiosa, a qual escondia um interrogatório que coletava informações sobre pais, domicílio, cor de cabelos dos irmãos. Desta maneira, as "irmãs pardas" peneiravam bairros, cidades, vilarejos e regiões, mapeando os potenciais alvos. Essa era a primeira fase do processo de sequestro e de apropriação. A segunda consistia em arrebatar a criança dos pais, quase sempre em procedimentos noturnos. Como regra geral, os pais não voltavam a ver seus filhos e, em certas situações, para evitar tumulto e reações hostis ostensivas, eles eram eliminados no momento do sequestro. A última fase do processo consistia na intervenção de médicos realizando minuciosos exames para detectar o caráter racial das vítimas e decidir sobre a validade ou não da assimilação de cada caso. Eles decidiam o destino das crianças: 
apropriação ou eliminação. A supressão dos vínculos paternos era o objetivo imediato implícito no trabalho de assimilação. Não foram raros os casos em que, mediante recursos de ordem psicológica e doutrinação com forte carga ideológica, as crianças sequestradas desenvolveram um esquecimento (induzido) muito rápido ou um sentimento de forte rejeição e ódio contra os pais biológicos. Situação semelhante estimulada por algumas famílias apropriadoras, na Argentina, mais de trinta anos depois.

Por outro lado, era necessário esconder dos pais adotivos a origem racial inferior da criança adotada, pois isso entrava em choque com o discurso racial nazista. $\mathrm{O}$ discurso repetido até a exaustão sobre o caráter inferior de outros povos europeus exigia que se escondesse a origem de muitas crianças assimiladas por uma necessidade demográfica deprimida. Os pais adotivos, quase sempre casais sem filhos, pressionados pela própria carga ideológica do discurso racista do nazismo, resistiam a adotar crianças de origem estrangeira e de pureza racial incerta. Sendo assim, o Lebensborn escondia o fato de repartir crianças raptadas; em tese, todas eram concebidas sob rigoroso "controle de qualidade" de sangue confiável ou, então, eram órfãs de pais falecidos em função das vicissitudes da guerra. Para todos os efeitos eram consideradas órfãs alemãs dos territórios da Europa Oriental. O Estado aproveitava o discurso semeado durante anos, sobre a existência de comunidades alemãs fora de fronteiras (a justificativa do pangermanismo histórico), para esconder a verdadeira origem das crianças. Quanto aos pais biológicos, os meninos e meninas sequestrados eram induzidos a esquecê-los, rejeitá-los ou, então, convencidos de que eles os haviam abandonado (o mesmo subterfúgio oferecido pelo Terrorismo de Estado do Cone Sul aos filhos de desaparecidos ou às crianças em processo de recuperação da verdadeira história e identidade). As crianças que resistiam a tal processo de manipulação e inversão da realidade acabavam eliminadas.

Em relação às meninas, a expectativa do Estado e das autoridades responsáveis era de que servissem, em médio prazo, como ventres à disposição do III Reich. Uma sobrevivente de Lódz (Polônia), Alycia Sosinka, 
menina sequestrada na época, ouviu das autoridades do local em que estava sendo reeducada: "Vocês porão no mundo dois ou três alemães de boa raça e depois desaparecerão...". ${ }^{16}$ Assim, as súditas estrangeiras racialmente "adequadas" eram conservadas ou eliminadas de acordo com as necessidades procriadoras:

[...] a pequena Alycia de Lódz, feita mulher demasiado depressa, teria o direito de dar à luz uma, duas ou três vezes numa clínica SS. Homens minuciosamente selecionados encarregar-se-iam de engravidá-la por prazer pessoal e por dever para com a pátria. Depois, um dia, um Dr. Ebner ${ }^{17}$ de plantão dar-lhe-ia uma injeção e Alycia teria deixado de existir. Assim se apagaria para sempre todo vestígio de contribuição de sangue estrangeiro para a obra de repovoamento ariano da futura Alemanha. ${ }^{18}$

O pós-guerra foi muito duro tanto com aquelas gerações procriadas nas residências do Lebensborn quanto para aquelas que foram germanizadas à força. As primeiras sofreram a rejeição por terem sido concebidas como a geração perfeita, a "super-raça" do Terceiro Reich. Muitas dessas crianças - ainda em orfanatos estatais quando a guerra acabou ou acompanhando mães acusadas, agora, de "colaboradoras" ou "prostitutas" - sofreram todo tipo de discriminação. A Noruega foi um dos países escolhidos pelos nazistas para aplicar o programa Lebensborn (por causa das características genéticas propícias, segundo o ordenamento ariano). Após a guerra, fracassou a iniciativa oficial de deportar à Alemanha as crianças geradas dentro daquele programa (também a tentativa alternativa de mandá-las para a Austrália). Elas acabaram confinadas em orfanatos e hospitais para doentes mentais. Discriminação, maus-tratos, violência física e psicológica foram sofrimentos cotidianos.

Em relação às crianças sequestradas, o fim da guerra trouxe uma situação um pouco diferente: o que fazer com elas? Nos casos em que isso era possível, a tentativa de reintegração se mostrou, em muitas situações,

${ }^{16}$ HILLEL, Marc. Op. cit., p. 198.

${ }^{17}$ Nota do autor: um dos médicos mais conhecidos do sistema Lebensborn.

${ }^{18}$ HILLEL, Marc. Op. cit., p. 200. 
demorada e dolorosa. O processo de germanização enraizara-se profundamente; muitos meninos e meninas viveram a separação dos pais adotivos como nova experiência traumática de dor e perda. Pais e filhos biológicos tiveram enorme dificuldade de se aceitarem mutuamente, e como se isso não bastasse, em uma Europa devastada. Por outro lado, como permitir que as vítimas de sequestro permanecessem com os pais de adoção se a relação que existia entre eles, independente dos sentimentos gerados, tinha origem em um violento processo de expropriação de uma jovem geração, verdadeiro "butim de guerra" humano? Em ambos os casos, os filhos do Lebensborn ficaram marcados na alma e na consciência pelo estigma de serem indesejados; como sólidos fantasmas, corporificavam concretamente, um duro e traumático passado. O silêncio oficial e coletivo ao seu respeito procurou esconder responsabilidades, evidências, omissões e colaboração. A intolerância e a discriminação fizeram recair o peso da culpa exatamente em cima daqueles que foram as principais vítimas do processo. Sofrendo a incompreensão da sociedade, o desconhecimento sobre a própria origem e punidos por constituírem um produto gerado desde o centro do poder nazista, a sua sobrevivência representa o trauma coletivo de lidar com um passado que deixou profundas sequelas e uma imagem espelhada que parece perguntar sobre as atitudes das gerações anteriores. Foram necessárias décadas para que, finalmente, essa história viesse a público através das vítimas-protagonistas remanescentes, marcadas pela indiferença e tratadas como párias, como se elas fossem autoras do crime que sofreram e cujos efeitos parecem nunca prescrever.

Finalizando, cabe ressaltar o paralelismo entre determinadas práticas repressivas nazistas e algumas modalidades existentes nas ditaduras de Segurança Nacional do Cone Sul. Encerrada a Segunda Guerra Mundial, algumas experiências de "guerra suja" e as práticas de Terrorismo de Estado acumuladas pelo nazismo foram incorporadas às práticas similares patrocinadas pelos EUA e seus aliados da OTAN, para aplicar nas guerras de libertação nacional, tendo a Guerra Fria como pano de fundo. ${ }^{19}$ Espe-

${ }^{19}$ DIETRICH, Heinz. Chile y la ‘innovación básica’ del Führer. Rebelión, Madrid, 13 sep. 
cialistas nazistas em técnicas de interrogatório e extermínio (sequestros, torturas e desaparições forçadas) foram cooptados para instruir, aperfeiçoar e atualizar as forças repressivas. A percepção da ameaça soviética global e a difusão do macarthismo no interior dos EUA levaram a CIA e a inteligência militar estadunidense a acelerar a implementação de programas para a apropriação dos conhecimentos da contra-insurgência nazista. ${ }^{20}$ Tais comparações estão longe de expressarem uma relação simplista e ideológica; ao contrário, o fato de respeitar a unicidade do fenômeno nazista, sua dimensão, suas especificidades e seu contexto histórico não impossibilita traçar a evolução das modalidades repressivas analisadas e encontrar raízes sólidas, históricas, que se projetaram sobre outros cenários geográficos e temporais.

\section{os soldados-mirins}

Uma das modalidades mais perversas de sequestro de crianças está ancorada no contexto da globalização, portanto, após a cronologia das experiências ocorridos no Cone Sul latino-americano. Trata-se da transformação de crianças e adolescentes em soldados de exércitos ou milícias em países conturbados por processos de desestruturação e rearranjos estruturais. Segundo dados da UNICEF, de 1996, a experiência dos soldados-mirins faz parte de um cenário maior de guerras e conflitos, crivados de interesses imediatos que muitas vezes mascaram a forte presença das potências extracontinentais, e que produziram a morte, mutilação, orfandade e invalidez de milhões de crianças. ${ }^{21}$

Traumas psicológicos, perda de lares ou afastamento dos pais são dramas que se reproduzem em escala inédita e que afetam, principalmente, po-

2003, [s.p.].

${ }^{20}$ IANNI, Octávio. Capitalismo, violência e terrorismo. Rio de Janeiro: Civilização Brasileira, 2004.

${ }^{21}$ CASTELLS, Manuel. Fim de milênio. A era da informação: economia, sociedade e cultura. São Paulo: Paz e Terra, 1999, v. 3, p. 186. 
pulações carentes de países empobrecidos ou subjugados por mecanismos de exploração internacional. São dinâmicas que envolvem conflitos entre civis e militares, grupos armados liderados por senhores da guerra, etc. As crianças são arrastadas a esses conflitos como soldados, em proporção crescente e essa não é uma realidade exclusiva do continente africano. Efetivamente, países tão diversos como Costa do Marfim, Sudão, Irã, Uganda, Bósnia, Colômbia e Moçambique, entre tantos outros, têm servido de palco para tais experiências. Milhares de crianças têm sido sequestradas das suas famílias, treinadas com extremo rigor, inclusive com métodos de tortura, para se tornarem guerreiros implacáveis, obedientes e violentos. São as mazelas sociais da pobreza, do desterro, da ignorância, da manipulação religiosa e ideológica que referenciam os marcos dessa situação. Apesar da maioria ser recrutada à força, são inúmeros os casos das que se juntam por desespero; ou seja, na sua forma mais explícita, muitas acabam recrutadas em troca de comida para si ou para suas famílias.

As crianças são fáceis de manipular e, em muitos casos, lutam tão bem quanto os adultos. Os menores são utilizados em tarefas de espionagem, guarda e combate de linha de frente. Já as meninas são usadas, preferencialmente, como escravas sexuais, mas também desempenham funções militares. Em 2007 especulava-se que do total de soldados-mirins existentes no mundo, 30\% eram meninas. Independente do sexo, uma das tarefas mais cruéis destinadas aos menores é o desarmamento de minas, o que de por si permite inferir o profundo descaso e desrespeito pelas suas vidas.

O recrutamento se dá através do medo, da indução, da promessa de poder ou de ajuda à família ou da simples extorsão física ou material. Muitas são sequestradas nas próprias escolas. As formas de coação não têm limites. Em Serra Leoa, por exemplo, antes de serem mandadas para operações de guerra recebiam um coquetel de pólvora e cocaína. Já na Libéria eram forçadas a passar por uma espécie de ritual no qual eram obrigadas a matar membros da própria família, sofrendo um brutal processo de desestruturação de valores, códigos e normas mínimas de convivência; tornaram-se, assim, reféns da lembrança desses crimes contra pais ou irmãos, 
alimentando sentimentos de culpa como se a responsabilidade por tais execuções fosse delas.

Por outro lado, treinamentos intensivos tornam-nas muito agressivas, parecendo guerreiros ferozes prontos para matar ou morrer, e desprovidos de discernimento do que seja guerra ou brincadeira. A utilização de armamentos leves e portáteis de enorme poder de fogo torna esses exércitos mirins extremamente letais, sobretudo contra populações desarmadas, alvos centrais de conflitos civis e étnicos. ${ }^{22}$

Um das situações mais emblemáticas corresponde à República Democrática do Congo, país onde, entre 1998 e 2002, mais de 30 mil meninos foram recrutados pelo governo e por quase uma dúzia de grupos insurgentes no conflito interno que abalou o país. Em 1996 ascendeu ao governo Laurent-Desire Kabila, vinculado ao tráfico de ouro e marfim. Kabila derrubou a longa ditadura de Mobutu Seko, mediante dura guerra civil de quase cinco anos contando para isso com apoio de países vizinhos (Ruanda e Uganda) e um exército do qual faziam parte milhares de crianças, os kadogo ("criança-soldado" em swahili, língua falada na África do Leste). ${ }^{23}$ Essa região foi cenário dos trágicos acontecimentos que produziram imagens que impactaram o mundo durante mais de uma década (o conflito entre as etnias tutsi e hutu). Os 32 anos de ditadura de Mobutu Seko e os cinco anos de guerra civil subsequentes deixaram o Congo à beira do caos e o sistema judicial totalmente desorganizado.

Posteriormente, muitas dessas crianças e adolescentes acabaram julgadas por crimes de guerra, como se fossem adultos. Houve casos de crianças de 15 anos condenadas à morte (caso de Mbako Banza). ${ }^{24}$ Esconde-se, porém, o fato de que os meninos que integraram bandos armados durante a guerra passaram anos separados das suas famílias. Aliás, esta é outra dimensão do

\footnotetext{
${ }^{22}$ Idem, p. 187.
}

${ }^{23}$ HARI, Johann. La tragedia del Congo: la guerra que el mundo olvidó. Rebelión, Madrid, 26 jun. 2006, [s.p.].

${ }^{24}$ SUNDARAM, Anjau. Niños rumbo al cadalso: pena de muerte en República Democrática del Congo. Rebelión, Madrid, 28 abr. 2006, [s.p.]. 
drama dos meninos-soldados. Muitos dos que conseguiram voltar, defrontaram-se com a rejeição familiar ou dos vizinhos, vítimas de bandos armados semelhantes aos que pertenceram. Ou seja, a possibilidade de reinserção dessas crianças nos seus meios sociais de origem tornou-se muito delicada. $\mathrm{O}$ mesmo vale para as meninas, aqui com o agravante de que muitas voltavam grávidas ou com filhos gerados durante o período em que estiveram sequestradas. Neste caso, a rejeição tanto foi direcionada contra elas quanto aos filhos nascidos na sua condição de escravas sexuais dos bandos armados. Em realidade, as garotas que retornam a suas comunidades são percebidas como tendo violado mais normas sociais do que os meninos. Elas têm dificuldades em se casar e seus filhos são frequentemente estigmatizados.

Outro desdobramento consiste na persistência de feridas psicológicas e sentimento de culpa que muitas dessas crianças carregarão pelo resto da sua vida. Considerando que poucas delas terão oportunidade de ajuda terapêutica, as sequelas de tal trauma poderão gerar distúrbios mentais ou comportamentais, ou ainda incidir em atos criminosos e na imersão em uma espiral de violência cotidiana sem volta.

É comum, também, que os menores que caem nas redes do sistema carcerário não conseguem pagar um advogado nem esclarecer a sua idade. Diante da falta de garantias dos direitos dos acusados, acabam tendo o seu destino predeterminado. A pena de morte contra estes menores, muitas vezes, é antecedida de interminável espera em situação carcerária acentuadamente indigna. De fato, trata-se de uma espécie de prisão perpétua. Em tese, o código penal, o qual prevê a pena de morte para determinados crimes, ilegaliza sua aplicação contra acusados menores de 18 anos. ${ }^{25}$ Entretanto, sofrendo uma situação de prisão indefinida e um tempo incerto, a lei acaba sendo burlada, pois os menores se tornam adultos e, a partir dessa condição, sofrem, então, a aplicação das penas mais duras.

No Congo, mesmo após os acordos que colocaram fim ao conflito, inúmeros senhores da guerra não participaram dos mesmos e continuaram

\footnotetext{
${ }^{25}$ Idem .
} 
recrutando crianças para servirem de soldados (mas também há casos de escravização e exploração sexual). O julgamento de um desses chefes militares, Thomas Lubanga, vinculado à União de Patriotas Congolenhos, no primeiro processo da Corte Penal Internacional, em Haya, serve para expor toda essa problemática. Entre os anos de 2002 e 2003 seu grupo continuou sequestrando crianças, algumas de até 10 anos, para lutar.

Segundo alguns especialistas, as crianças que foram transformadas, sem opção e contra a sua vontade, em soldados-mirins não deveriam ser punidas pelos crimes cometidos. Pois, apesar de tudo, somente eram crianças cumprindo ordens. O advogado da promotoria Ekkehard Withopf alegou, na corte que Lubanga treinou meninos para matar, ordenou que matassem, e deixou que morressem em confrontos. ${ }^{26}$ Nos últimos anos, a pressão internacional consolidou o entendimento de que os soldados-mirins detidos devem ser tratados como vítimas e ser acolhidos por um processo de recuperação e reinserção. Mesmo timidamente, a UNICEF e a Corte Penal Internacional parecem apontar para a consolidação dessa tendência. Quer dizer, qualquer menor que no ato do sequestro ou cooptação, tenha sofrido coação material, física, moral ou psicológica, pode exigir a qualificação de vítima; isto também vale para as reconhecidas vítimas indiretas, caso dos pais. ${ }^{27}$

A tragédia dos soldados-mirins deixa um rastro de destruição de uma geração de crianças. Centenas de milhares delas foram retiradas à força do convívio familiar, sob a truculência da ação estatal ou de grupos armados. A complexidade e diversidade da violência sofrida são imensuráveis. A convivência com a morte, com a violência sexual, física, psicológica e moral, a falta de discernimento de valores, a degeneração dos princípios de convivência, a solidão resultante da separação do entorno que dá sentido e todo tipo de carência afetiva se combinam com a não-experimentação da infância, tempo perdido e, muitas vezes, irreversivelmente comprometido.

\footnotetext{
${ }^{26}$ MATEOS, Oscar. Miliciano congoleño a juicio. Rebelión, Madrid, 1 feb. 2007, [s.p.].

${ }^{27}$ MANSOUR, Fati. Los crímenes de Ituri por fin salen de las sombras. Rebelión, Madrid, 27 ene. 2009, [s.p.].
} 
Mesmo assim, conhecidos todos estes fatos, continuam tímidos os avanços jurídicos e a pressão internacional; em fevereiro de 2009, estimativas da própria ONU indicavam a existência, ainda, de mais de 250 mil soldados-mirins espalhados em mais de dez países. ${ }^{28}$

\section{"Butim de guerra" no cone sulzq}

No Cone Sul das ditaduras de Segurança Nacional e do Terrorismo de Estado, ${ }^{30}$ as políticas de desaparecimento constaram como a metodologia mais sofisticada em termos de repressão política. O contexto de impunidade foi a base para as ações repressivas estatais de cunho arbitrárias, numa demonstração ostensiva por parte dos executores, os quais pensavam ter imunidade perpétua. Protegidos por essa "armadura" que tornava pouco crível que sofressem no futuro aplicação de sanções ou reparações, os agentes repressivos tiveram mais sucesso na imobilização e amedrontamento da sociedade ante uma repressão exercida sem restrições, ${ }^{31}$ o que aumentou a sensação de impotência das vítimas e do seu entorno.

O contexto de impunidade para ações repressivas, sob o "guarda-chuva" protetor da "obediência devida" às ordens superiores e no cumprimento do dever, foi obtido através da aprovação de leis que obstruíram iniciativas que exigiam aplicação de justiça e medidas reparatórias. O medo, a hostilização, as ameaças, a indução ao silêncio e ao esquecimento reforçaram

${ }^{28}$ Unicef liberta 85 crianças e jovens recrutados por milícias no Congo. Folha Online, 3 fev. 2009, [s.p.].

${ }^{29}$ Este item, com o título "A guerra contra as crianças: práticas de sequestro, desaparecimento e apropriação de identidade no século XX - 'Butim de Guerra' no Cone Sul da Segurança Nacional", foi publicado nos Anais eletrônicos do XI Encontro Estadual de História: história, memória e patrimônio, da ANPUH-RS, ocorrido na Universidade Federal do Rio Grande, em 2012.

${ }^{30}$ Referência às ditaduras de Segurança Nacional existentes, nas décadas de 60 a 80, na Argentina, Brasil, Bolívia, Chile, Paraguai e Uruguai.

${ }^{31}$ CONADEP. Nunca Mais. Informe da Comissão Nacional Sobre o Desaparecimento de Pessoas na Argentina. Porto Alegre: L\&PM, [s.d.], p. 175. 
a sensação de impunidade. Esta também justificou atitudes irresponsáveis como o mentir deliberadamente aos familiares que procuravam informações sobre o destino das vítimas. Pistas absurdas foram oferecidas como iscas diversionistas: "Los desaparecidos están en Cuba o en Nicaragua"; "fueron secuestrados por la guerrilla"; "não existem desaparecidos", "son una invención de los subversivos". ${ }^{32}$

A violência contra crianças também marcou a etapa repressiva. Milhares delas foram obrigadas a conviver com famílias separadas e sofrer com a satanização dos entes queridos, o isolamento e a marginalização sentida na escola, na vizinhança ou na própria família. Milhares delas sofreram com a prisão dos pais, a imersão na clandestinidade ou partilharam das condições sempre difíceis do exílio. Todas essas crianças sofreram as consequências de uma dinâmica que as colheu como vítimas, nos influxos de uma lógica que tiveram de suportar irremediavelmente e com múltiplas perdas e incompreensões.

Entre todas elas, há o caso particular dos filhos de mortos e desaparecidos. Além de terem passado por algumas das experiências traumáticas citadas, essas crianças foram vítimas de outra, marcada por elementos muito particulares, que colocam, de forma mais complexa, a dimensão da irreparabilidade das perdas. A ausência de pais sobre os quais se desconhece seu destino gera, com o passar do tempo, uma espécie de presença fantasmagórica, que dilui lembranças, apaga imagens ou torna irreconhecível a existência daqueles. Tal situação pode ser amenizada pela presença e o trabalho persistente de outros familiares que contribuam no intuito de preencher parte desse quebra-cabeça tão sensível, oportunizando o acesso a informações, imagens, atitudes, idéias e lembranças vitais para dar certa concretude ao ausente. Os filhos dos desaparecidos políticos tiveram que aprender a aceitar que aqueles rostos tão jovens, plasmados em poucas fotos, eram, sim, o reflexo da imagem dos pais. E, de forma traumática, precisaram de muitos anos para descobrir, contra a propaganda oficial do Estado

\footnotetext{
${ }^{32}$ MOLINA THEISSEN, Ana Lucrecia. La desaparición forzada de personas en América Latina. KO'AGA ROÑETA, série VII, 1998.
} 
autoritário, que não foram abandonados pelos pais e que a sua ausência não foi uma opção de sobrevivência.

Dentro de tal universo, entretanto, há um caso que extrapola, ainda mais, esses limites tão extremados: o das crianças que foram sequestradas, desaparecidas e apropriadas. ${ }^{33}$ Tal fenômeno ocorreu principalmente na Argentina, mas também atingiu o Uruguai e, secundariamente, envolveu outros países da região. Na sua grande maioria, são filhos de pais assassinados e desaparecidos, mesmo que não tenham consciência disso (no caso dos que permanecem sequestrados) ou lembrem da experiência traumática sofrida (o sequestro). A apropriação de crianças, quase sempre, esteve vinculada a uma espécie de comércio das mesmas (por dinheiro, troca de favores ou vantagens pessoais). Nas experiências dos regimes de Segurança Nacional, reconhecer o crime de apropriação de crianças implica em descobrir a existência de um mecanismo sequestro-desaparecimento-apropriação que é resguardado na permissividade e/ou cumplicidade do centro do poder estatal, o qual possibilitou que um ser indefeso fosse arrancado do convívio da família de origem e tivesse um nome e uma história imposta, apagando, assim, todo seu passado. ${ }^{34}$

Transformadas em "butim de guerra", a procura das crianças apropriadas se constituiu em enorme desafio para superar essa profunda ferida aberta do passado recente argentino e uruguaio. Os dados com que trabalham as organizações de direitos humanos, particularmente Abuelas de Plaza de Mayo, apontam para aproximadamente 550 crianças vítimas de sequestro e apropriação, muitas delas em ações da Operação Condor. Até o início de 2009, 99 delas foram recuperadas e tiveram a identidade restituída.

\footnotetext{
${ }^{33}$ Ver também: PADRÓS, Enrique Serra. "Botim de Guerra: desaparecimento e apropriação de crianças durante os regimes civil-militares platinos". MÉTIS: história \& cultura, 11, 2007, pp. 141-161.

${ }^{34}$ MADRES Y FAMILIARES DE URUGUAYOS DETENIDOS DESAPARECIDOS. A Todos Ellos. Informe de Madres y Familiares de Uruguayos Detenidos Desaparecidos. Montevideo: 2004, p. 526.
} 
Luís Eduardo Duhalde ${ }^{35}$ destaca os objetivos por detrás dessa operação, todos justificados pela lógica de combater o "inimigo interno", segundo as pautas da Doutrina de Segurança Nacional: a) produzir terror na população; b) vingar-se e fustigar seus familiares; c) interrogar as crianças com discernimento; d) quebrar o silêncio dos pais, torturando os filhos; e) beneficiar-se com as crianças como "butim de guerra"; f) educar os filhos menores com uma ideologia contrária à dos pais. De qualquer forma, sejam quais forem os motivos dos sequestros é essencial considerar que todos eles foram fundamentados pela existência de uma impunidade, percebida como perpétua, pelo sistema repressor.

A seguir, apontamos para o caso de Mariana Zaffaroni, um dos mais emblemáticos e comoventes envolvendo o sequestro e apropriação de crianças no marco da coordenação repressiva no Cone Sul dos anos 70. Destacamos que a singularidade do caso, paradoxalmente, se reveste de universalidade porque, independente do entorno particular de cada uma das situações e experiências específicas, todas elas são fruto de um contexto que lhes dá sentido e de uma política sistemática de apropriação dos filhos daqueles que, por sua vez, foram vítimas de extermínio.

O caso Mariana Zaffaroni foi um dos que mais comoveu a sociedade uruguaia (e também a argentina). A menina, sequestrada junto com os pais, em 1976, em Buenos Aires, tinha um ano e meio de idade. Após anos de procura, as avós a localizaram junto a um casal de apropriadores argentinos. Através da justiça, a família biológica tentou recuperar a menina. Enquanto seguiam os trâmites na justiça, a avó María Ester recebeu duas cartas extensas, assinadas por Daniela Furci, o nome dado ilegalmente a Mariana. Tal fato constituiu mais uma agressão contra a família biológica e, particularmente, contra essa avó. Mariana, na época, tinha nove anos e era evidente que as cartas, que emitiam complexos conceitos políticos, filosóficos e morais e citações bíblicas, bem de acordo com as diretrizes autoritárias vigentes, só podiam ser de autoria do sequestrador. Recheadas de ${ }^{35}$ DUHALDE, Eduardo Luís. El Estado terrorista argentino. Quince años después, una
mirada crítica. Buenos Aires: Eudeba, 1999. 
acusações inverossímeis, as cartas aludiam, ainda, à vida familiar da menina, atingindo a família biológica, uma vez que fazia referência constante a pais e avós que, de fato, não o eram (pois eram a família apropriadora). Numa dessas cartas dizia: ${ }^{36}$

[...] Cuanto odio sentirá Ud. por mí y por mi familia, claro mis papis me enseñan lo mejor y me educan como buenos cristianos que son. No me imaginan usando uniforme y recibir instrucción militar aceptando las enseñanzas y doctrinas de algún Partido, como Ud. les habrá inculcado a sus hijos. Esto se lo digo por simple deducción... si no explíqueme qué hacían en mí país su hija y su yerno en vez de estar en el Uruguay, unidos todos en el seno familiar, ¿quiénes eran? ... ¿guerrilleros? [...].

Há várias passagens em que Mariana/Daniela, a suposta autora do texto, conta detalhes do seu dia-a-dia, reforçando o amor recíproco que sentem ela, mãe e pai. Visando magoar, acrescenta:

A las 12.00 del mediodía - como siempre - 1lama la ABUELA DELIA y casi hace las mismas preguntas que a las $13.00 \mathrm{hs}$. me hace la ABUELA ZULEMA... Como estás mi amor?... estás jugando?... tomaste toda la leche?... almorzaste, yo a todo respondo en forma afirmativa y luego les corto, sin antes mandarles 1.000 .000 de besos - entendió bien señora, 1.000 .000 de besos para mis ABUELAS.

Quando finalmente a justiça se pronunciou a favor da prisão dos Furci, eles fugiram para o Paraguai, levando a menina. Mariana foi sequestrada pela segunda vez. Casos de famílias de repressores e apropriadores que fugiram para o Paraguai, após o fim da ditadura argentina, temendo a ação da justiça diante dos crimes cometidos, foi um sinal bem claro da sobrevivência das redes protetoras vinculadas à coordenação repressiva do Condor e a confiança na imobilidade da ditadura Stroessner, garantindo segurança e nova documentação para a imersão dessas famílias em um processo de blanqueamiento de identidade. Assim, os Furci, escondidos no Paraguai, sumiram sem deixar rastos, protegidos pela persistência do esquema repressivo regional, intocável. Diante da passagem do tempo, as avós María

\footnotetext{
${ }^{36}$ Carta de 21 ene. 1985. In: SALABERRY, Mariela. Mariana, tu y nosotros. Montevideo: Banda Oriental, 1993, pp. 141-145.
} 
Ester e Martha quiseram deixar algum registro para a menina; passaram a escrever-lhe cartas para que em algum futuro, distante ou não, pudesse saber delas, dos seus sentimentos e dos seus verdadeiros pais:

Mariana:

Si por casualidad puedes leer esto o alguna persona conocida te lo puede transmitir, yo quisiera que tú supieras que fuiste esperada con mucho amor por tu madre, tu padre y toda tu familia.

Tus padres no te abandonaron. Tus abuelas te buscamos desde el primer momento. [...]

Mariana, no podemos hacer nada de esto. Sólo juntar nuestros recuerdos, escribírtelos y hacértelos llegar como un regalo, para que cuando lo llegues a leer - porque llegará ese día - veas en estas líneas tu presencia constante en nuestras vidas y el anhelo sin límite de compartir tu existencia. $^{37}$

Passaram-se outros tantos anos até que a pista dos Furci fosse retomada e, finalmente, o casal apropriador foi encontrado e julgado. Em 1993, a justiça se pronunciou: sete anos de prisão para o homem e três para a mulher. Porém, não houve o final feliz desejado pelas avós. A reação de Mariana surpreendeu: rejeitava sua verdadeira história, seu nome e o contato com a família biológica; pior, manifestava carinho pelos pais apropriadores. Obrigada pela justiça, aos 18 anos fez o teste de sangue que confirmou o que já se sabia. A justiça também lhe restituiu seu verdadeiro nome, mas não conseguiu restituir-lhe os sentimentos que naturalmente teria desenvolvido se não tivesse sido vítima de um crime dessa magnitude. O juiz Marquevich lembra que ordenou ao Registro Nacional de las Personas que mudasse o nome da jovem. Daniela Romina Furci devia deixar de existir para que Mariana tivesse sua identidade restituída. Sabedor do drama íntimo da menina afirmou: "Es un acto que parece administrativo, formal. Pero es como una muerte. Esa persona ya no está más”. ${ }^{38}$ Estela

${ }^{37}$ Carta de María Ester Gatti. In: SILVA, Alberto. Perdidos en el bosque. Montevideo: Familiares de Detenidos-Desaparecidos, 1989, p. 39.

${ }^{38}$ Trespuntos, Buenos Aires, 29 jul. 1998, p. 32. 
de Carlotto, presidente de Abuelas de Plaza de Mayo, na ocasião, opinou de forma diferente: "La primera muerte de Mariana y de todos los chicos es la apropriación. Ahí la hacen desaparecer y loa hacen nacer falsamente. Al devolverle la identidad nosotros no decimos que mataron a [Daniela] Romina Furci, decimos que revivieron a Mariana. Vuelve la vida", ${ }^{39}$

A vida de Mariana, a partir dessa nova situação, foi marcada por incertezas, dúvidas e rejeição. No secundário, teve que elaborar uma redação cujo título era Una joven busca empleo. O resultado é um complexo testemunho sobre suas dificuldades diante de um mundo construído sob alicerces falsos que estava desmoronando e outro novo, mas completamente desconhecido:

Un hombre uniformado de gris me preguntó: “Nombre y apellido?” ¿qué hubiera contestado? ¿Que durante toda mi vida mi gente me llamó Daniela Furci; pero que ahora hay gente que dice que me llamo Mariana Zaffaroni Islas? ¿Que el nombre que llevé durante toda mi vida y que me dieron mis padres - que ahora están presos por habérmelo dado - no es legalmente el mío? Preferí sentirme ilegal antes que traidora. Así que respondí: Daniela Romina Furci. “¿Nacionalidad?” Soy argentina. Pero tengo dos orígenes diferentes. Uno de padres uruguayos, subversivos. El otro de padres argentinos. Mi padre luchaba del otro lado. Un día yo llegué a él y él eligió entre pegarme un tiro en la cabeza o cuidarme como la hija que nunca pudo tener. Su humanidad y su deseo de ser el mejor padre del mundo lo llevó a la segunda opción. Ahora lo está pagando como si me hubiera matado. $[\ldots]^{40}$

Mariana responsabilizou a família biológica pela prisão do casal Furci e continuou vivendo com a avó materna adotiva. Após anos desejando abraçá-la, as avós e as tias biológicas descobriram que a moça de 18 anos que tinham na sua frente, no Juzgado de San Isidro (Buenos Aires), estava muito distante das fotografias e das lembranças que tinham motivado sua procura incessante, procura que fora um verdadeiro símbolo para a sociedade uruguaia durante a campanha do plebiscito convocado para reverter

\footnotetext{
${ }^{39}$ Idem, p. 32.

${ }^{40}$ Idem., p. 31. 
a anistia aos crimes de Estado, em 1989. As sequelas do sequestro e da apropriação, neste caso, foram resultado das práticas mais perversas do Terrorismo de Estado; práticas essas implementadas para que não tivessem somente efeitos no momento da sua aplicação, mas que se multiplicassem sobre o tempo futuro e sobre as gerações futuras. Aos olhos de Mariana, seus pais adotivos não eram apropriadores que ficaram com ela a partir de uma delicada premissa anterior - a de que os pais verdadeiros haviam sido assassinados pelo mesmo regime que encobriu e encorajou seu sequestro e que contou, em suas fileiras, com repressores como Furci.

No Juzgado, o encontro entre as avós e as tias com Mariana foi muito duro. A jovem tão procurada, tão querida pela família biológica, teve uma atitude fria, distante; nem no pior pesadelo as avós poderiam imaginar a rejeição encontrada.

- Mariana: ¿Y si no me hubieran buscado?

- Tía Cecilia: ¿Qué hubieras pensado tú, después que te enterás que tenías una familia, si esa familia te hubiera dejado abandonada y no te hubiera buscado? ¿Qué hubieras pensado?

- Mariana: ¿Y nunca pensaron en mí, nunca pensaron en mí dolor?

- Abuela Maria Ester: ¡Cómo no! Si habremos pensado en ti que te estuvimos buscando 16 años. Permanentemente. $\mathrm{Y}$ ahora comprendemos el dolor y la confusión que deberás estar sintiendo. Pero tú, ¿alguna vez pensaste en nosotros? ¿Pensaste que nos mataron los hijos? ¿Pensaste que lo único que nos dejaron sos tú? Y Marta [a outra avó biológica] tiene más hijos y más nietos. Pero yo, ahora, lo único que me queda sos tú. ${ }^{41}$

No meio de tanta dor, a avó María Ester chegou a externar o seguinte: "Pienso que Mariana en algún momento va a cambiar; cuando sea mayor, cuando sea madre, quizá. Va a sentir otros sentimientos, distintos a los que tiene ahora. Claro que yo ya no voy a estar, sus tiempos son distintos a los míos". ${ }^{42}$ De fato, o tempo passou. Mariana se formou em Direito e teve

\footnotetext{
${ }^{41}$ SALABERRY. Op. cit. , p. 100.

${ }^{42}$ Trespuntos, Buenos Aires, 29 jul. 1998, p. 31. 
uma filha. A esperança da avó María Ester parcialmente se concretizou. A maternidade fez Mariana repensar. Provavelmente, lembrou da mãe, o que a motivou a aproximar-se da antiga família, dos avós verdadeiros, mesmo para estabelecer uma relação marcada por sentimentos divididos, desconfiança e contradições. Entretanto, pouco tempo restou. Durante 17 anos foi procurada e, quando sua verdadeira identidade foi restituída, seguiram-se anos de rejeição. Quando decidiu tomar a iniciativa, os avôs já haviam falecido, e a avó Martha mal conseguia abraçar a neta e a bisneta, falecendo pouco depois. ${ }^{43}$

O caso Mariana reflete um dos maiores traumas produzidos pelas políticas repressivas de Estado. As famílias que viveram tal violência sofreram perdas humanas irrecuperáveis, perda de tempo - atrás da ilusão do reencontro de netos e sobrinhos. E quando os reencontros se tornaram possíveis, foram bem diferentes do imaginado. Tiveram que aceitar que as pessoas recuperadas estavam divididas, com afetos desenvolvidos aos responsáveis pelo seu sequestro e apropriação, talvez até responsáveis pela morte dos verdadeiros pais. Tiveram que aceitar que era preciso dar tempo; um tempo indefinido, o tempo do amadurecimento para enfrentar tamanha situação, mas um tempo escasso para muitos avôs e avós. E para a criança/ adolescente/jovem de identidade restituída, uma terrível situação de descobertas que lhe exige muito. Perdas, descobertas, decepções, angústia, sentimentos divididos, todo um sistema de valores e uma estrutura familiar que se desmorona como um castelo de cartas e, como saldo, a penosa reconstituição de tudo isso.

A experiência traumática de Mariana Zaffaroni se reflete, de forma diversa, em tantos outros casos semelhantes, o que enseja algumas reflexões. É inegável que o Terrorismo de Estado devastou o entorno real dessas crianças sem elas terem plena consciência disso. Também sofreram uma violência invisível através da apropriação e da sonegação da identidade. Ao tornarem-se públicos os crimes cometidos pelos pais apropriadores, essas crianças (algumas, já como adolescentes, e os casos atuais, como adul-

${ }^{43}$ LIMA, Samarone. Clamor. Rio de Janeiro: Objetiva, 2003, p. 203. 
tas) viram o seu entorno, sustentado em crimes e mentiras, ser brutalmente agredido; desconhecendo o motivo originário, reagiram defensivamente, procurando protegê-lo. Por outro lado, está a violência interminável sofrida pelas famílias que procuraram. Perderam os filhos, provavelmente em situações brutais; mesmo assim persistiram na busca de toda e qualquer pista que pudesse levar aos netos, último vestígio do que restou dos projetos dos filhos. Os mais velhos consumiram a energia dos últimos anos num mano a mano contra a passagem do tempo. Angústias, incertezas, impunidade e solidão diante do Estado e da justiça acentuaram as dificuldades. Finalmente, um pouco afastada da centralidade desses protagonistas, mas não por isso secundária, uma violência que atingiu e continua atingindo em cheio a sociedade como um todo. A persistência dos sequestros, os reencontros desencontrados e a ineficiência ou demora da ação da justiça prolongam uma dor e indignação coletiva em amplos setores da sociedade, sintomas concretos da eficiência de um sistema repressivo que semeou violência, impunidade e medo para o futuro.

Mariana, ao igual que outros casos semelhantes, na lenta e difícil aproximação da família biológica e ao tomar consciência do significado da sua procura, ${ }^{44}$ da dimensão do drama e do esforço vivido pelos avós verdadeiros, talvez tenha sentido remorsos por ter demorado os abraços aguardados. Porém, ela não é culpada disso; não sendo a única vítima dessa história, Mariana sempre foi e será a maior vítima desse processo.

Inegavelmente há uma responsabilidade particular do Estado pela falta de cooperação e obstaculização impostas às demandas apresentadas pelos familiares. Ao não agir no esclarecimento da situação, com as ferramentas legais que possuía e que teriam permitido esclarecer informações solicitadas, as autoridades pouco têm feito para que após tantos e tantos anos o crime

\footnotetext{
${ }^{44} \mathrm{O}$ rosto e os olhos da pequena Mariana, com um ano de idade, foram uma das principais peças de mobilização da cidadania uruguaia que tentou impedir em vão, no plebiscito de 1989, a confirmação da lei que anistiava os crimes cometidos pelo Estado durante a ditadura uruguaia. Vinte anos depois, Mariana Zaffaroni, embora de forma discreta, acompanha o novo plebiscito que tenta revogar o resultado daquele. Tal fato demonstra que, embora lento, o processo de buscar as suas origens e recuperar elementos da sua identidade, efetivamente está ocorrendo.
} 
continue se perpetuando nessa nefasta combinação de impunidade, inércia, conivência e cumplicidade, legado de um Terrorismo de Estado que ainda encontra significativos remanescentes no sistema político e na postura corporativa e no "pacto de silêncio" das Forças Armadas. Mesmo assim, um avanço. A legislação internacional, hoje, considera imprescritíveis os crimes de detenção-desaparecimento, tortura e apropriação de crianças.

No Cone Sul, o tema concernente às crianças desaparecidas persiste. Seu particularismo desloca para um plano secundário outras crianças que também sofreram os efeitos daquelas experiências discricionárias (dos filhos dos executados; das crianças que conviveram com as mães nas prisões; das que sofreram o trauma da separação dos pais, das visitas aos cárceres, do exílio; ou simplesmente das que foram vítimas de sistemas de ensino fraturados por diretrizes e doutrinas autoritárias). Mariana Zaffaroni continua a sua vida. E o processo de recuperação da sua identidade, dura, dolorida, traumática continua. Em 2009, dentro desse processo de aproximação, reaproximação e recuperação de identidade enviou um e-mail que comoveu muita gente. Como uma "garrafa jogada ao mar", com uma carta dentro, Mariana mostrou que estava pronta para dar um salto qualitativo nesse longo processo de recuperação da identidade roubada/apagada:

\section{Quiero conocer a mis padres 45}

Y.... al fin llegó el día... QUIERO CONOCER A MIS PADRES... y como solo puedo reconstruirlos les pido a uds, que los conocieron que me los acerquen.

De la misma forma, les pido que reenvíen este mail a otros compañeros y amigos que pudieron haberlos conocido (ya que no tengo el correo de nadie mas) para que me puedan contar cosas, chicas, grandes, importantes, nimias, de su militancia, de sus ideas, de lo que hacían y de lo que les gustaba, cualquiera para poder armar el rompecabezas de quienes eran. Cualquier pequeño detalle será bien apreciado, yo, lamentablemente no tengo de ellos ningún recuerdo, por eso agradeceré enormemente a todos Uds. que si los tengan, que los compartan conmigo.

45 Disponível em: http://colectivoepprosario.blogspot.com.br/2009/10/uruguay-mariana-zaffaroni-hoy-por-la.html Acesso: 6 de maio de 2012. 
Les ruego me disculpen si les pido que recuerden cosas dolorosas, si es así, lo sabré entender. Imagino que es difícil contestar sin ninguna pregunta concreta, la verdad es que tampoco se que preguntar... no se ¿que música les gustaba? ¿Que hacían cuando se juntaban con amigos? ¿Donde les gustaba salir a pasear? que se yo... ¿como eran conmigo?... bueno, no se... repito, cualquier historia será bien recibida.

Desde ya muchísimas gracias a todos.

Un beso.

Mariana Zaffaroni

Mariana recebeu inúmeras mensagens de antigos companheiros dos pais, espalhados pelo mundo. O impacto da sua atitude gerou uma onda de solidariedade que até então ela não tinha percebido. Um dos companheiros do pai escreveu um livro sobre seus pais, como forma de poder contar a ela quem eram aqueles jovens militantes (Los padres de Mariana). Mariana hoje está integrada à luta política pelo resgate da memória da geração dos seus pais e pela exigência de punição dos crimes cometidos pela ditadura uruguaia. Ela continua tendo relação com a família apropriadora, mas também tem participado da Marcha do Silêncio que todo 20 de maio lembra os desaparecidos uruguaios, carregando as fotos dos seus pais desaparecidos, e a lembrança da avó Maria Ester, falecida em dezembro de 2010. Mariana continua procurando informações sobre seus pais e o que aconteceu com eles; mas desde alguns anos, também procura pistas sobre um hipotético irmão que pode ter nascido em cativeiro. A caminhada de mariana pela recuperação da sua história e do resgate da história truncada dos seus pais, continua, e certamente está longe de acabar.

$* * * * * * * * * * * * * * *$

A aproximação aos casos apresentados permite observar que, em processos de violência estatal de dimensões colossais (a experiência nazista), ou nos conflitos restritos às dimensões de um só país (Espanha franquista), ou de uma região concreta (o Cone Sul latino-americano) bem como no processo gelatinoso que dilui responsabilidades diante dos efeitos produzidos pelo impacto da globalização neoliberal sobre as populações mais pobres da África, dentre as vítimas centrais as crianças sempre ocupam lugar de destaque. A extrema facilidade com que são afetadas por situações adversas, condições de abandono 
(miséria, orfandade, trabalho infantil, deslocamento demográfico), necessidades materiais de sobrevivência, regimes de força ou práticas sofisticadas de apropriação política, racial ou religiosa apontam para uma condição de fragilidade, por um lado, e de cobiça, por outro. Se os efeitos econômicos indiretos de tendência estrutural assinalam situações de altíssimo risco na periferia africana, isso não diminui a gravidade de conjunturas que geram fenômenos extremados nos centros econômicos e políticos constituídos a mais tempo.

A combinação dos efeitos e das mazelas do imperialismo, do colonialismo, do anticomunismo histórico e das rivalidades presentes durante a Guerra Fria são alguns dos fatores que permitem contextualizar determinados fatos e processos. A doutrinação, o trabalho escravo, a prostituição e a militarização das quais são vítimas mostram que, enquanto tesouro a ser conquistado, as gerações mais novas são sempre alvo de disputas que, embora centradas numa perspectiva político-ideológica, extrapolam-na. Um menino-soldado cumpre o seu papel ao defender um senhor da guerra africano ou dar a vida pelo Führer; uma menina polonesa tem utilidade ao cumprir com a missão de gerar filhos para o domínio ariano, enquanto filhos de republicanos são moralmente induzidos a expiar os crimes dos pais e os dos "subversivos" latino-americanos a odiar os valores ético-políticos dos seus progenitores. Nesse sentido, a vida infantil pouco vale nos tensos cenários de estruturas colapsadas da experiência africana; é valorizada como fator de reprodução e de doutrinação nos casos europeus citados; e é percebida como o maior troféu sobre o inimigo vencido (derrotá-lo ao extremo de roubar-lhe os filhos, a própria descendência). Se é bem verdade que as fronteiras entre centro-periferia têm se diluído, relativamente, no passar das últimas décadas, desenhando-se, talvez, como o modelo arquipélago indicado por Ignácio Ramonet, ${ }^{46}$ também é verdade que, independente de fazer parte do centro ou da periferia, os filhos dos perdedores, nos múltiplos sentidos desta expressão, são alvo e cobiça dos vencedores.

${ }^{46}$ RAMONET, Ignácio. O modelo arquipélago. In: . Geopolítica do caos. Petrópolis: Vozes, 1998. 
